\title{
Behavioural responses to heat in desert birds: implications for predicting vulnerability to climate warming
}

\author{
B. Smit ${ }^{*}$, G. Zietsman², R. O. Martin², S. J. Cunningham², A. E. McKechnie ${ }^{3}$ and P. A. R. Hockey ${ }^{2}$
}

\begin{abstract}
Background: Temperature increases associated with climate change pose a substantial threat to arid-zone bird species. However, predicting vulnerability to high temperatures using species-specific, mechanistic data, and assessing how this varies within and among species, is complex, time consuming and expensive. Using the bird community of the southern Kalahari Desert, we investigated whether interspecific variation in heat dissipation behaviour (HDB) thresholds could provide an index of vulnerability to high temperatures. We fitted logistic regression models to presence/absence data for behaviours as a function of air temperature $\left(T_{\text {air }}\right)$ in order to determine, for each species, the $T_{\text {air }}$ at which panting and gular flutter (pant $\left.t_{50}\right)$, wing-drooping $\left(\right.$ wing $\left._{50}\right)$, resting (rest $t_{50}$ ) and shade-seeking (shade ${ }_{50}$ ) responses occurred in $50 \%$ of instances.

Results: We show that pant $t_{50}(n=30$ species) is higher in species that 1$)$ are smaller, 2) maintain low activity levels at high $T_{\text {air }}$, and 3 ) rely mostly on food as their water source (i.e. non-drinking species) - the only predictor variable to remain significant in phylogenetically-independent analyses. Like pant ${ }_{50}$, wing $_{50}(n=30$ species) was negatively correlated with body mass, but did not vary systematically with other organismal traits. There was no systematic variation in shade ${ }_{50}\left(n=33\right.$ species) or rest $t_{50}(n=14$ species) values.

Conclusions: Our findings suggest that evaporative cooling demands are relatively higher in larger birds and could limit activities (such as foraging) at $T_{\text {air }}$ s exceeding $30{ }^{\circ} \mathrm{C}$, while the trade-off between thermoregulation and sustaining activity levels appears less pronounced in smaller species. Kalahari species that do not drink regularly show a relatively greater dependence on wing-drooping compared to panting/gular flutter, probably resulting from selective pressures to reduce evaporative cooling demands in an arid environment with scarce surface water. Two key questions remain to be answered to confirm whether variation in HDB thresholds provides an opportunity for rapid assessment of vulnerability to high temperatures in avian species from hot, arid environments. First, what are the relationships between HDB patterns and body temperature regulation? Second, is heat dissipation effort indicative of dehydration risk?
\end{abstract}

\section{Background}

A key challenge facing researchers seeking to predict the impacts of climate change on animals concerns the tradeoff between single-species models based on in-depth studies of physiological and behavioural processes, versus more generalised correlative models that can yield predictions for entire communities. Recent decades have seen substantial

\footnotetext{
* Correspondence: ben.smit@nmmu.ac.za

'Deceased

'Department of Zoology, Nelson Mandela Metropolitan University, PO Box 77000, Port Elizabeth 6031, South Africa

Full list of author information is available at the end of the article
}

conceptual development in both these fields. Bioclimatic envelope models (BEMs) have rapidly become a popular prediction tool for large scale changes in the distributions of organisms in response to climate warming [1-4]. BEMs rely on quantifying the climate envelope currently inhabited by a species, then using outputs from global circulation models to predict where, geographically, suitable climate conditions for the species will occur in future. The attractiveness of this method and its popularity over the last two decades $[1,5,6]$ is due in no small measure to the relative ease and rapidity with which predictions for multiple species can be generated. 
In contrast to BEMs, mechanistic models predict species' niches based on detailed understanding of ecological and physiological processes. Detailed parameterisation of mechanistic models relies on intensive and time-consuming sampling of focal taxa. To date, this approach has focussed predominantly on single species [7-10], limiting inference over the potential impact of climate change on communities. Despite the difficulties of building and parameterising complete mechanistic models, empirical mechanistic studies have provided convincing insights into how particular species and populations are affected by climate, particularly in response to high temperatures (e.g., [11-19]).

Birds inhabiting hot, arid environments provide a useful model system for developing novel approaches to predicting species' vulnerabilities to increasing temperatures, combining mechanistic underpinnings with the potential to rapidly and cheaply generate predictions for entire communities. In these habitats, operative temperatures (a measure of the overall environmental heat load experienced by an animal [20]) routinely approach or exceed avian body temperature $\left(T_{\mathrm{b}}\right)$ [21]. This creates conditions where the need to conserve water and avoid dehydration is in direct conflict with reliance on evaporative cooling to avoid lethal hyperthermia [17, 22-25]. Occasionally, periods of extremely hot weather cause catastrophic mass mortality events, sometimes involving thousands of individuals $[26,27]$. Even at air temperature $\left(T_{\text {air }}\right)$ below avian $T_{\mathrm{b}}$, metabolic heat gain, or heat gained from solar radiation, means that birds must frequently dissipate excess heat via evaporative and non-evaporative mechanisms, such as panting/gular flutter and wing-drooping, respectively [14, 28-30]. The demands of heat dissipation behaviour (HDB) can lead to trade-offs that have potentially far-reaching implications for body condition, survival and reproduction [13, 31, 32].

Recent studies in southern Africa's Kalahari Desert highlight the links between easily-observable patterns of behaviour and variables that directly impact survival and reproduction [13-16, 31]. For example, du Plessis et al. [13], found a negative correlation between $T_{\text {air }}$ and body mass $\left(M_{\mathrm{b}}\right)$ gain of Southern Pied Babblers (Turdoides bicolour) during summer, such that on hot days (i.e. maximum $T_{\text {air }}>35.5{ }^{\circ} \mathrm{C}$ ) the birds' $M_{\mathrm{b}}$ gain during the day was insufficient to balance typical overnight $M_{\mathrm{b}}$ loss. Reduced $M_{\mathrm{b}}$ gain appeared to be driven by reduced foraging efficiency on hot days resulting from conflicts between dissipating heat by panting and simultaneous foraging [13].

Relatively little is known about the effects of high $T_{\text {air }}$ on behavioural and physiological responses in free-ranging birds [13, 14, 16, 33], and more specifically, how these vary at an inter-specific level with organismal variables such as $M_{\mathrm{b}}$ and ecological attributes (e.g. behaviour, diet and microhabitat use) [34]. Although we expect the time allocated to heat dissipation to increase at high $T_{\text {air }}$ we can also make several predictions regarding interspecific variation in HDB.

First, larger birds have been shown to initiate evaporative cooling responses at lower temperatures compared to smaller birds [35], presumably reflecting their lower surface area-volume ratios and increasing thermal inertia with increasing $M_{\mathrm{b}}$. Hence, we might predict that during hot weather, trade-offs between HDB and time allocated to activities, such as foraging and maintenance behaviours, should be more pronounced in larger species.

Second, we expect that the ecological significance of such trade-offs is greater in species with overall higher activity levels. For example, species that are active gleaners, and whose foraging mode involves nearconstant activity, presumably generate a greater metabolic heat load per unit time while foraging, compared to sit-and-wait foragers.

Third, respiratory HDB, in particular panting and gular flutter, is associated with high evaporative water loss (EWL) requirements. We may therefore expect species relying solely on food as a water source to depend to a lesser extent on respiratory EWL and more on passive heat loss mechanisms such as wing-drooping. These species may also show lower activity levels and spend less time in the sun to reduce evaporative cooling demands.

We test whether HDB varies in a predictable manner among bird species from the southern Kalahari. Should HDB thresholds vary predictably (as outlined above), then we believe behaviour is likely to be both a good proxy for investigating the ecological significance of thermal physiological trade-offs, and useful in understanding ecological and evolutionary determinants of species persistence in hot, arid landscapes.

\section{Methods \\ Study sites}

Data were collected at three different sites within the southern Kalahari: Tswalu Kalahari Reserve (S27 ${ }^{\circ} 19^{\prime}$, E22 $\left.25^{\prime}\right)$, Dreghorn Game Ranch (S26 $52^{\prime}$, E20 $\left.43^{\prime}\right)$ and Kuruman River Reserve (S26 $58^{\prime}$, E2 $\left.2^{\circ} 49^{\prime}\right)$. All sites were located within the arid savannah biome of the Northern Cape Province of South Africa. Mean annual rainfall data values were obtained from private rangeland owners. At Tswalu Kalahari Reserve, mean annual rainfall over a 30-year period was $295 \pm 172 \mathrm{~mm}$ (coefficient of variation, $\mathrm{CV}=58.3 \%$ ) (D.N. MacFadyen, unpublished data). Mean annual rainfall at a ranch near Kuruman River Reserve and Dreghorn Game Ranch was lower at $\sim 190 \pm 125 \mathrm{~mm}(\mathrm{CV}=66 \%)$ over a 60 -year period (G. Scholtz, unpublished data). Long-term $T_{\text {air }}$ data were not available for these sites. Habitat type at all three study sites was savannah on red sand dunes with 
no natural free-standing surface water sources, although there were artificial water troughs in the reserves/ranches.

\section{Weather data}

During our study we obtained weather data using a portable weather station (Vantage Pro2, Davis Instruments, Hayward, CA), set $2 \mathrm{~m}$ above the ground at a central location within each study site. The $T_{\text {air }}$ recorded during our study ranged from 18.9 to $38.9{ }^{\circ} \mathrm{C}$ (record maximum $T_{\text {air }}$ was $37-38.9{ }^{\circ} \mathrm{C}$ at all the sites during the study).

\section{Behavioural observations}

Behavioural observations of birds were conducted during austral summers (November-March) of 2009/2010 and 2010/2011. We collected a total of 11,110 observations during the study at all the sites; 4673 observations at Tswalu Kalahari Reserve during the first summer, and 4243 during the second. We also collected 2148 observations at Dreghorn Game Ranch and 62 at Kuruman River Reserve during the second summer. The small numbers of observations from Kuruman River Reserve were included to boost observations for a few target species (e.g. Crimson-breasted Shrike, Laniarius atrococcineus). Behavioural observations were conducted during the warmer part of the day (between 10:00 $\mathrm{h}$ and 18:00 $\mathrm{h}$ ) when bird behaviour was likely to be affected most by high temperatures. We conducted observations by searching for birds while walking, or from a vehicle. Walking observations were conducted in 426 plots (approximately $800 \mathrm{~m} \times 100 \mathrm{~m}$ in size) that we selected at random within the landscape. These plots were separated by at least $500 \mathrm{~m}$, and were a minimum of $500 \mathrm{~m}$ from the nearest surface water source. The majority of the plots were sampled only once (414 plots, 3545 observations), and plots sampled on the same day were always more than $1 \mathrm{~km}$ apart. A subset of 12 plots at Tswalu Kalahari Reserve were surveyed 18 times each, at varying times of day and on days of varying maximum air temperature (total of 5546 observations); during repeated sampling of these plots there may have been some degree of pseudoreplication as some individual birds may have been observed more than once. Within each plot, we searched for birds over a period of $30 \mathrm{~min}$ to $1 \mathrm{~h}$ by moving from one end to the other at an average speed of $\sim 0.5 \mathrm{kmh}^{-1}$ stopping regularly to scan the surroundings for birds. Driving observations were obtained ad-hoc while driving in a motor vehicle along an un-surfaced track (a total of 235 tracks, 2019 observations) between 1 and $10 \mathrm{kmh}^{-1}$ for $30 \mathrm{~min}$ to $1 \mathrm{~h}$; each track was only sampled once. We stopped the motor vehicle at regular intervals and scanned for birds; birds were generally more conspicuous when approached from the vehicle than by foot.

During observation periods, each bird seen was identified to species level, and we recorded the presence $(=1)$ or absence $(=0)$ of HDB; if HDB could not be assessed = NA (Not Applicable). Heat dissipation behaviours were categorised as either respiratory HDB, or nonrespiratory HDB. Panting (defined as gaping when breathing) and gular flutter (rapid movement of the gular area) behaviours are well known avian respiratory HDBs associated directly with evaporative cooling and increased EWL rates [23, 28-30, 36, 37]. Wing-drooping behaviour (defined as holding the wings away from the body) is often recorded as a mechanism to increase the surface area of the body to enhance radiative and convective dry heat loss by exposing thermal windows under the wing $[28,37]$. Both these categories of behaviours are easily observable in the field [13, 14, 31]. In addition we recorded activity state (mobile $=1$, resting $=0$ ) and exposure (full sun $=1$, associated with vegetation shade $=0$ ) during the observation event. Behavioural assessment of each individual generally lasted around $30 \mathrm{~s}$.

With the exception of ambush flights (sallying or pouncing), birds in flight were not recorded, and aerial foragers, such as swifts and swallows, were therefore excluded from the study. In addition, birds were not recorded if their behaviour appeared to have been altered by the presence of the observer, or if the bird was observable for too short a time for behaviours to be determined with certainty. If more than one individual of the same species was encountered and it was considered that the behaviour of each individual was not independent of the other birds in the group (e.g. they were foraging together as a flock) then a judgement of the predominant behaviour of the group was made.

\section{Statistical analyses}

\section{Analysis of heat dissipation behaviour}

We calculated two types of indices for heat dissipation behaviour:

(1)We determined the relationships between $T_{\text {air }}$ and binomial behaviour data for each species separately by performing logistic regression analyses, using a logit link-function and quasi-binomial probability density function to account for over-dispersion, in $\mathrm{R}$ [38]. In cases where the beta estimate was significant at the $95 \%$ confidence level, or approached significance (i.e. fell between 95 and $90 \%$ confidence level), we used model predictions to determine, for each species, the $T_{\text {air }}$ at which the behavioural response was present in $50 \%$ of observations, i.e. median $T_{\text {air }}$. Median $T_{\text {air }}$ values of panting and gular flutter (pant $\left.t_{50}\right)$, wing-drooping $\left(\right.$ wing $\left._{50}\right)$, resting $\left(\right.$ rest $\left._{50}\right)$ and shade-seeking (shade ${ }_{50}$ ) were calculated as the intercept value (absolute) divided by the beta value (absolute). 
(2)For each species we extracted all the data recorded at hot $T_{\text {air }}\left(35-40{ }^{\circ} \mathrm{C}\right)$ during our study. We then counted all the instances where each species was panting, wing-drooping, mobile, and in full sun, and calculated proportional values from the total number of observations at hot temperatures for each species; hereafter referred to as prop_pant, prop_wing, prop_act, and prop_sun, respectively. These proportional values provided us with a supplementary index of behaviour in each species.

Previous studies have found a link between humidity, heat load and the demands for evaporative cooling in birds [14, 39]. Specifically, Smit et al. [14] found that White-browed Sparrow-Weavers had higher $T_{\mathrm{b}} \mathrm{s}$ when vapour pressure deficits were below $2 \mathrm{kPa}$. During the current study, vapour pressure deficits were sometimes below $2 \mathrm{kPa}$ during rainy periods. Observations associated with vapour pressure deficits below $2 \mathrm{kPa}$ made up a very small proportion of our data, and prevented us from conducting adequate statistical analyses to account for humidity. Excluding data associated with low vapour pressure deficits $(<1 \mathrm{kPa},<2 \mathrm{kPa},<3 \mathrm{kPa}$, in a step-wise manner) did not affect our pant $t_{50}$ estimates. We therefore included all observations in this study, regardless of vapour pressure deficit and did not include humidity as a variable in our analyses.

\section{Interspecific analyses}

We performed both generalized linear models (GLS) and phylogenetic generalized linear models (PGLS) in $\mathrm{R}$-the latter using the ape [40] and caper [41] packages, to test for systematic differences in median $\mathrm{T}_{\text {air }}$ values of behaviour ( pant $_{50}$, wing s0 $_{50}$, shade s0 $_{0}$ and rest $t_{50}$ ). In PGLS analyses we used Kappa transformations to estimate phylogenetic signal in the null models for each dependent factor. We included $\log _{10}$ body mass $\left(\log _{10} M_{\mathrm{b}}\right)$, diet, foraging location, drinking dependency, prop_act, and prop_sun (defined above) as independent variables in the global models (prop_act and prop_sun were excluded from rest $t_{50}$ and shade 50 models, respectively). Foraging location was grouped into arboreal versus terrestrial foragers; diet was grouped into frugivores, granivores, omnivores and insectivores (insectivores and carnivores pooled); and drinking dependency was grouped into non-drinking or drinking species based on their reliance on freestanding surface water. All above groupings were based on Hockey et al. [42]. We included prop_act and prop_sun as independent variables since we expected high levels of activity and sun exposure to be associated with heat dissipation behaviours.

We sampled 100 phylogenies for all the species in our dataset from http://www.birdtree.org [43] using the Hackett et al. [44] phylogeny as a back-bone. We used the majority consensus tree identified using the programme Mesquite [45]. For each dependant variable we initially ran a global model with all the independent variables as listed above. We then used multi-model inference [46], using the R package "MuMIn" [47] to select the top three models. We based our model selection on Akaike Information Criteria corrected for small sample sizes (AICc) values. We calculated the variance inflation factors for all independent factors in the global models. Although variance inflation factors were never $>5$, we found that $\log _{10} M_{\mathrm{b}}$ and prop_act were correlated (Pearson's correlation coefficient $=0.72$ ). We therefore tested the effect of $\log _{10} M_{\mathrm{b}}$ on prop_act using both GLS and PGLS. In these analyses we performed a logit-transformation on prop_act values, following Warton and Hui [48]. In addition, "diet" was slightly collinear with drinking dependency (variance inflation factor $=4$ ) and was subsequently excluded from most global models.

To test our hypothesis that non-drinkers avoid evaporative cooling to conserve water, we calculated the differences between pant 50 and wing $_{50}\left(\right.$ wing $_{50}-$ pant $\left._{50}\right)$ values for 17 species and tested if the magnitude and direction of wing $_{50}-$ pant $_{50}$ differences were explained by drinking dependency, including $\log _{10} M_{\mathrm{b}}$ and prop_act as covariates in GLS and PGLS analyses.

\section{Results}

We obtained data from 76 species during the study (see Additional file 1: Table S1 and Additional file 2), and were able to calculate statistically significant estimates of median $T_{\text {air }}$ values for pant $_{50}$, wing ${ }_{50}$ and shade 50 for 33 species, and rest $t_{50}$ values for 13 species (see Additional file 1: Table S2 and Additional file 3). Kappa values in pant $_{50}$ and shade $_{50}$ were 1.00 and 0.762 , respectively, but only approached significance from zero $(p=0.064$ and $p=0.051$, respectively). The Kappa value of wing $_{50}$ was not significantly different from zero $(K=0.571, p=$ 0.196). Our sample size for rest $t_{50}$ values was smaller than the minimum number of species needed to obtain a phylogenetic signal [49]. In contrast, we found significant phylogenetic signals in prop_act $(K=0.843, p<0.01)$, and $\log _{10} M_{\mathrm{b}}(K=0.673, p<0.05)$.

Median $T_{\text {air }}$ values for different categories of HDB varied widely: pant 50 values ranged from 31.3 to $46.0{ }^{\circ} \mathrm{C}$ (mean $39.3^{\circ} \mathrm{C}$ ), whereas wing $_{50}$ values ranged from 35.3 to $44.6{ }^{\circ} \mathrm{C}\left(38.9^{\circ} \mathrm{C}\right)$ (Figs. 1 and 2). For 19 species, we were able to obtain estimates of both pant $t_{50}$ and wing $g_{50}$ (Fig. 2.). For a further six species, we found a significant response in only wing ${ }_{50}$, but not pant $t_{50}$, and vice versa for another six (Additional file 1: Table S2; Fig. 2). We found that rest $_{50}$ and shade $_{50}$ values were generally lower than pant $t_{50}$ and wing ${ }_{50}$, and ranged from 6.7 to $38{ }^{\circ} \mathrm{C}\left(\right.$ mean $\left.=24.6{ }^{\circ} \mathrm{C}\right)$ in rest ${ }_{50}$, and 14.2 to $54{ }^{\circ} \mathrm{C}\left(30.3{ }^{\circ} \mathrm{C}\right)$ in shade 50 (Fig. 3). 


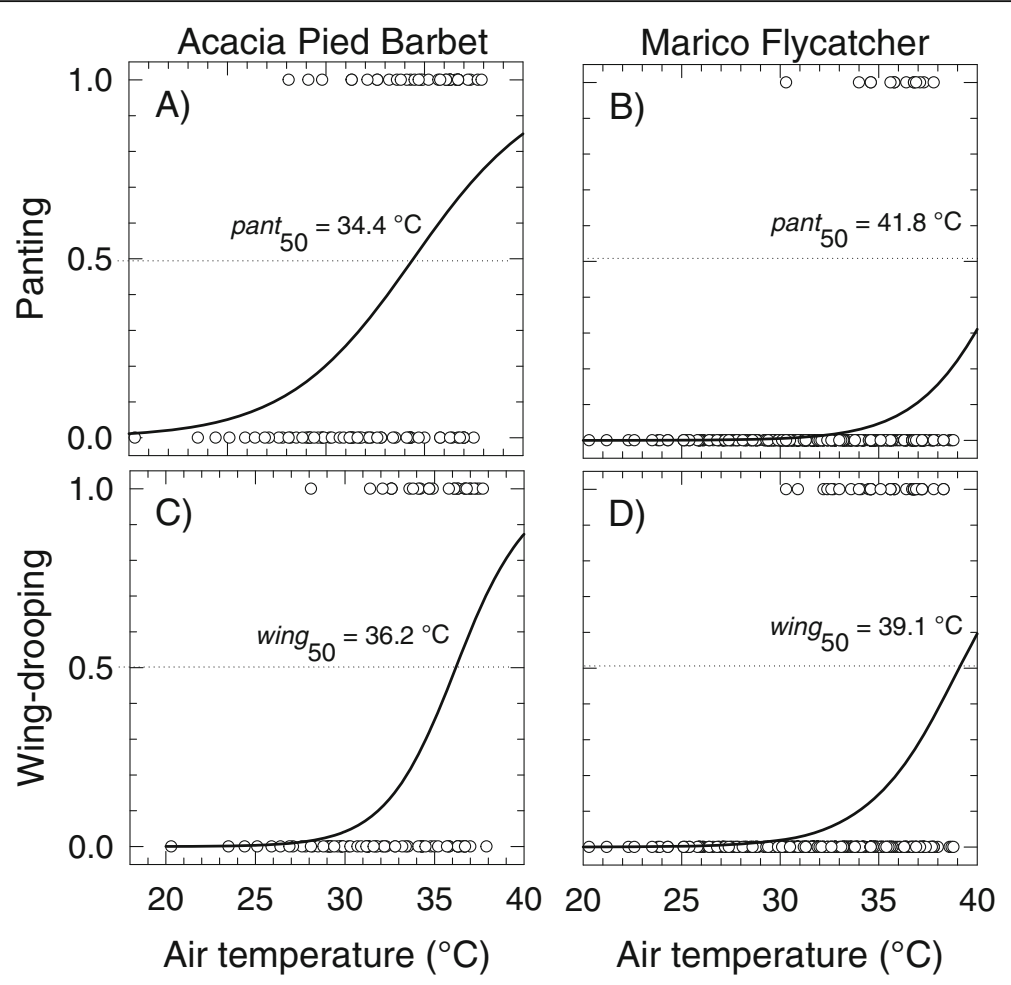

Fig. 1 Heat dissipation behaviour representing presence/absence of $(\mathbf{a} \& \mathbf{b})$ panting, and $(\mathbf{c} \& \mathbf{d})$ wing-drooping as a function of air temperature $\left(T_{\text {air }}\right)$ in two avian species in the Kalahari Desert; Acacia Pied Barbet, Tricholaema leucomelas $(32 \mathrm{~g})$, and Marico Flycatcher, Bradornis mariquensis $(26 \mathrm{~g}$ ). Presence of the behaviour $=1$, and absence of the behaviour $=0$. The logistic regressions represent predicted proportion of heat dissipation. Significant $(p<0.05)$ relationships are indicated by solid trendlines. Median $T_{\text {air }}$ values where panting

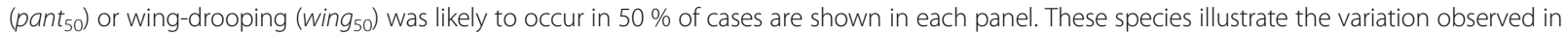
their heat dissipation responses to $T_{\text {air }}$ (see Additional file 1: Table S2, for statistics); whereas Acacia Pied Barbet showed relatively low pant ${ }_{50}$ and wing $_{50}$ values, Marico Flycather showed relatively high pant ${ }_{50}$ and wing $_{50}$ values

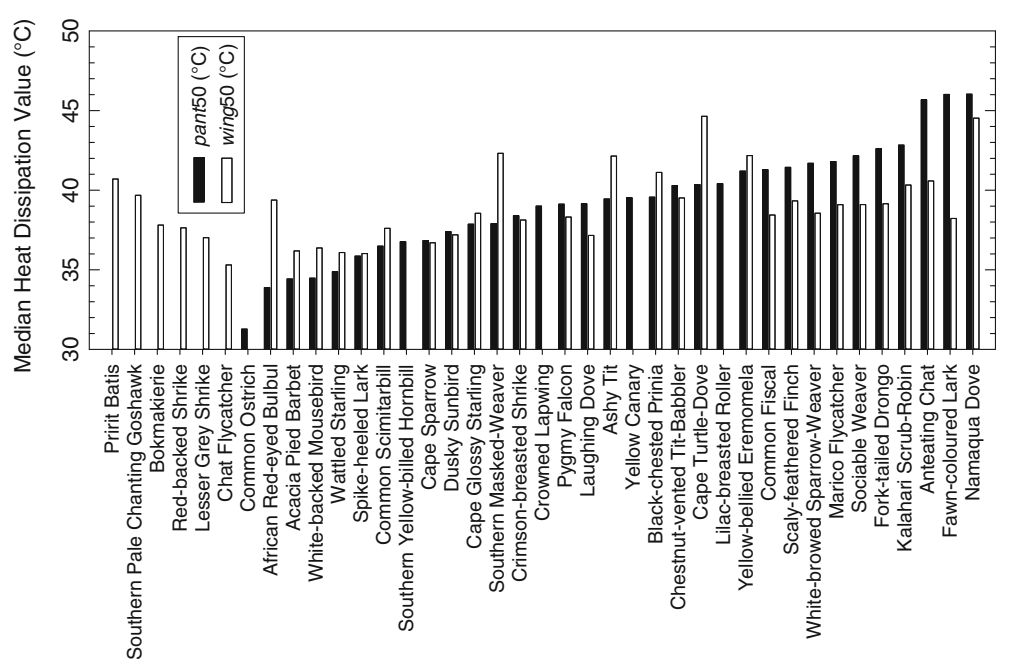

Fig. 2 Median $T_{\text {air }}$ values where panting (pant ${ }_{50}$, black bars) or wing-drooping (wing ${ }_{50}$, white bars) was likely to occur in $50 \%$ of cases in Kalahari Desert bird species 


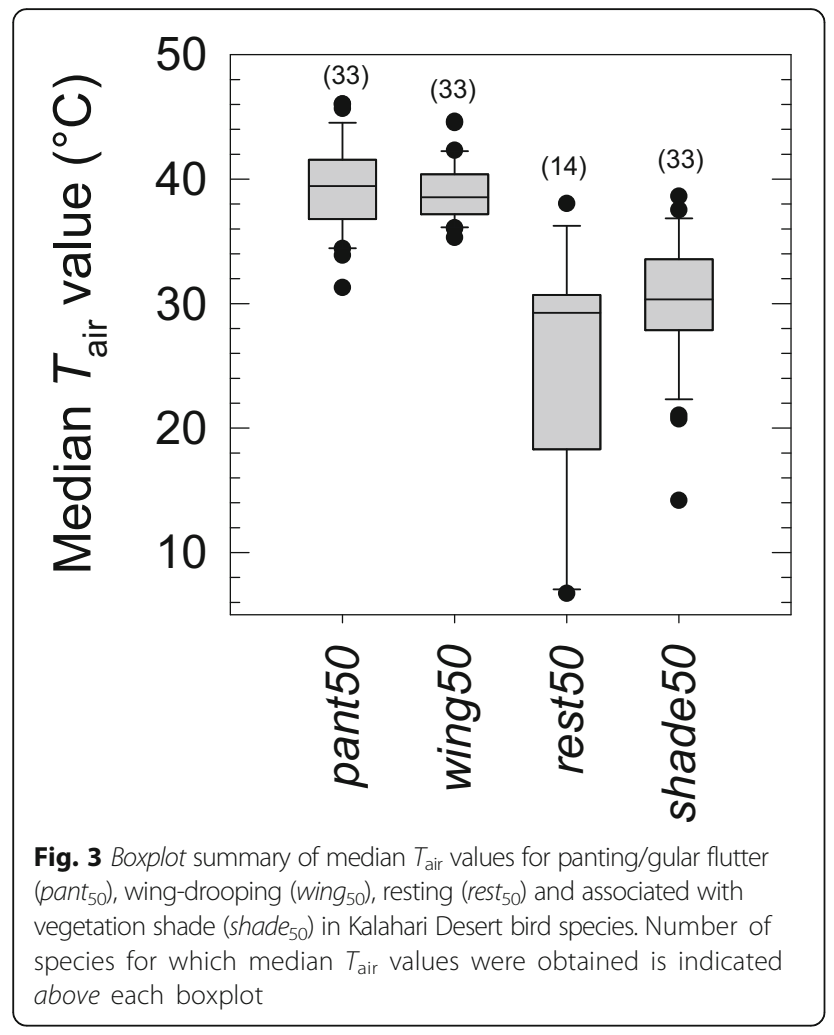

We excluded data from Common Ostrich (Struthio camelas, $M_{\mathrm{b}}>60 \mathrm{~kg}$ ) from our multi-species analyses because this species is several orders of magnitude larger than the remaining species from which we obtained HDB data (9 to $\sim 800 \mathrm{~g}$ ). We also excluded Namaqua Dove (Oena capensis) and Spike-heeled Lark (Chersomanes albofusciata) from pant to $_{50}$ analyses; Namaqua Dove, Cape Turtle Dove (Streptopelia capicola) and Southern Pale Chanting Goshawk (Melierax canorus) from wing 50 ; and Ant-eating Chat (Myrmecocichla formicivora) from shade $_{50}$ analyses, as their respective median values were highly influential outliers based on Cook's distance.

\section{Models for pant ${ }_{50}$}

A conventional GLS analysis identified $\log _{10} M_{\mathrm{b}}$, prop_act and drinking dependency as important explanatory variables in the top three most highly weighted models of pant $t_{50}$ (Table 1). We found that pant $t_{50}$ was significantly negatively correlated with $\log _{10} M_{\mathrm{b}} \mathrm{t}_{1,25}=$ -3.62, $p<0.01)$ and prop_act $\left(\mathrm{t}_{1,25}=-4.05, p<0.001\right)$, and significantly higher in non-drinking species (mean pant $_{50} \pm \mathrm{SD}, 40.7 \pm 2.6^{\circ} \mathrm{C}, n=20$ ) compared to drinking species $\left.\quad\left(36.9 \pm 2.4 \quad{ }^{\circ} \mathrm{C}, \quad n=10\right) \quad \mathrm{t}_{1,25}=3.86, \quad p<0.001\right)$ (Fig. 4). Whereas both foraging location and prop_sun were influential in some of the top models, these variables did not show a significant effect on pant $t_{50}(p>0.1)$

Table 1 Three top-weighted models explaining median $T_{\text {air }}$ values in panting/gular flutter behaviour (pant ${ }_{50}$ ) using both generalized linear models (GLS) and phylogenetic independent analyses (PGLS). The global model included: $\log _{10}$ body mass $\left(\log _{10} M_{\mathrm{b}}\right)$; proportion of observations where birds were mobile (prop_act), and exposed to full sun (prop_sun) at air temperature between 35 and $40{ }^{\circ} \mathrm{C}$ (see methods for details); drinking dependency; foraging location; and diet as independent variables. Only the variables that were influential in the three top-weighted models are shown. For each variable we provide the contrast ( \pm standard error), and significance level (see note below Table)

\begin{tabular}{|c|c|c|c|}
\hline & \multicolumn{3}{|l|}{ Model } \\
\hline & 1 & 2 & 3 \\
\hline & GLS & & \\
\hline $\log _{10} M_{b}$ & $-5.62 \pm 1.56^{* *}$ & $-5.06 \pm 1.57^{* *}$ & $-5.29 \pm 1.56^{* *}$ \\
\hline prop_act & $-7.69 \pm 1.91^{* *}$ & $-7.79 \pm 1.97^{* *}$ & $-6.73 \pm 2.02^{* *}$ \\
\hline Drinking dependency (non-drinking) & $3.12 \pm 0.81^{* *}$ & $2.94 \pm 0.83^{* *}$ & $3.12 \pm 0.80^{* *}$ \\
\hline Foraging location (terrestrial) & $1.32 \pm 0.79$ & & $1.54 \pm 0.79$ \\
\hline prop_sun & & & $2.86 \pm 2.20$ \\
\hline Intercept & $48.30 \pm 3.15^{* *}$ & $48.20 \pm 3.26^{* *}$ & $46.57 \pm 3.38^{* *}$ \\
\hline Observations & 30 & 30 & 30 \\
\hline \multirow[t]{2}{*}{$\mathrm{AICC}$} & 136.4 & 136.4 & 137.8 \\
\hline & PGLS & & \\
\hline prop_act & & & $-1.56 \pm 2.20$ \\
\hline Drinking dependency (non-drinking) & $4.08 \pm 1.06^{* *}$ & $4.04 \pm 1.15^{*}$ & $3.95 \pm 1.09^{*}$ \\
\hline prop_sun & $5.07 \pm 2.42$ & & $-4.59 \pm 2.55$ \\
\hline Intercept & $34.44 \pm 2.72^{* *}$ & $36.07 \pm 4.04^{* *}$ & $35.05 \pm 2.88^{* *}$ \\
\hline Observations & 30 & 30 & 30 \\
\hline $\mathrm{AICC}$ & 159.7 & 161.7 & 161.8 \\
\hline
\end{tabular}

Note: ${ }^{*} p<0.05 ;{ }^{* *} p<0.01$ 

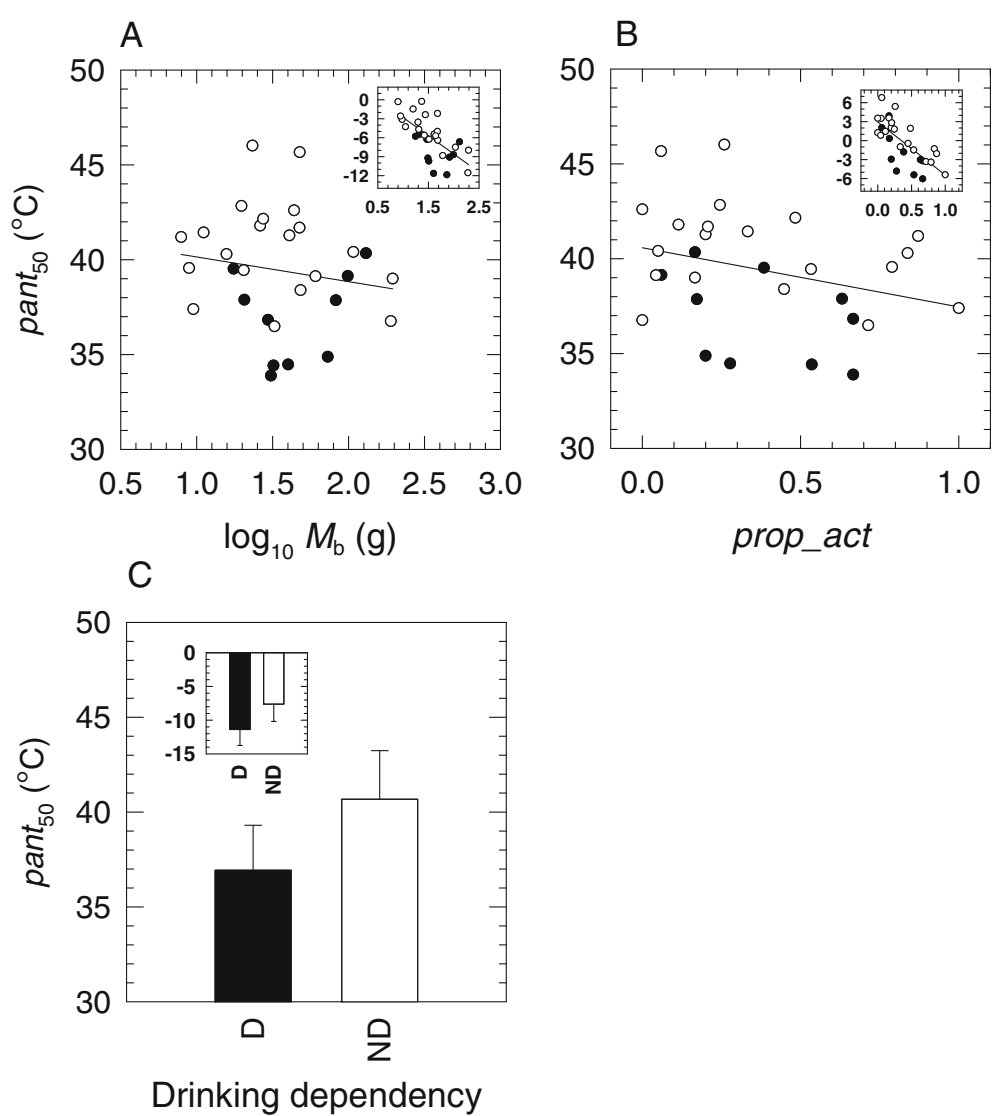

Fig. 4 Median $T_{\text {air }}$ values for panting/gular flutter (pant $\left.t_{50}\right)$ were significantly related to $(\mathbf{a}) \log _{10}$ body mass $\left(\log _{10} M_{\mathbf{b}}\right)$ (negative relationship), b prop_act (negative relationship), and c drinking dependency (D: drinking species; ND: non-drinking species); pant 50 was lower in species that rely on surface water. The insets represent partial residuals of the model including all three above-mentioned variables. The filled and clear circles represent drinking and non-drinking species, respectively

(Table 1). A PGLS analyses showed that drinking dependency was the most important explanatory variable in all the top weighted models, and non-drinking species had significantly higher pant $_{50}$ values compared to drinking species $\left(\mathrm{t}_{1,28}=3.86, p<0.001\right)$ (Table 1$)$. The top performing model included a positive correlation with prop_sun as an explanatory variable that approached significance $\left(\mathrm{t}_{1,28}=2.10, p=0.051\right)$.

\section{Models for wing $_{50}$}

A conventional GLS showed that $\log _{10} M_{\mathrm{b}}$ best explained variation in wing w $_{50}$ in the top three most influential models (Table 2); wing 50 was significantly negatively correlated with $\log _{10} M_{\mathrm{b}}\left(\mathrm{t}_{1,28}=-2.85, p<0.01\right.$; Fig. 5). Although drinking dependency and prop_act were important in models 2 and 3, neither of these had a significant effect on wing so (all $p>0.7$ ) (Table 2). In contrast, a PGLS analysis showed that $\log _{10} M_{\mathrm{b}}$ and prop_sun were influential in some of the models, but did not perform better than the null model; none of these factors had a significant effect on wing $g_{50}$ $\left(\log _{10} M_{\mathrm{b}}: p=0.08\right.$; prop_sun: $\left.p>0.30\right)$ (Table 2$)$.

\section{Comparing pant ${ }_{50}$ and wing $_{50}$}

For species for which both pant 50 and wing 50 could be calculated, drinking species showed mean pant 50 and wing $_{50}$ values of $37.6 \pm 3.7{ }^{\circ} \mathrm{C}(n=10)$ and $39.2 \pm$ $3.4{ }^{\circ} \mathrm{C}(n=10)$, respectively, and these were correlated (Pearson correlation coefficient $=0.752$ ). Non-drinking species showed mean ( \pm SD) pant 50 and wing $_{50}$ of $40.7 \pm 2.6{ }^{\circ} \mathrm{C} \quad(n=18)$ and $39.2 \pm 1.5{ }^{\circ} \mathrm{C} \quad(n=18)$, respectively, and these values were not correlated (Pearson correlation coefficient $=0.244$ ). Both a GLS and PGLS showed that prop_act and drinking dependency significantly predicted the magnitude and direction of wing $_{50}-$ pant $_{50}$ (Fig. 6). Proportion activity was significantly positively correlated with wing $_{50}-$ pant $_{50}$ (GLS: $\mathrm{t}_{1,25}=3.33, p<0.01$; PGLS: $\mathrm{t}_{1,25}=2.52, p<0.05$ ); species with high activity demands showed wing $_{50}$ values higher than pant 50 values (Fig. 6). Nondrinking species showed a greater difference between wing $_{50}$ and pant $_{50}$ values than drinkers (GLS: $\mathrm{t}_{1,25}=$ -3.94, $p<0.001$; PGLS: $\left.\mathrm{t}_{1,25}=-3.55, \quad p<0.01\right)$; nondrinkers initiated panting at higher $T_{\text {air }} \mathrm{s}$ than wingdrooping (Fig. 6). 
Table 2 Three top-weighted models explaining median $T_{\text {air }}$ values in wing-drooping behaviour (wing ${ }_{50}$ ) using both generalized linear models (GLS) and phylogenetic independent analyses (PGLS). The global model included: $\log _{10}$ body mass ( $\log _{10} M_{\mathrm{b}}$ ); proportion of observations where birds were mobile (prop_act), and exposed to full sun (prop_sun) at air temperatures between 35 and $40{ }^{\circ} \mathrm{C}$ (see methods for details); drinking dependency; foraging location; and diet as independent variables. Only the variables that were influential in the three top weighted models are shown. For each variable we provide the contrast ( \pm standard error), and significance level (see footnote below Table)

\begin{tabular}{|c|c|c|c|}
\hline & \multicolumn{3}{|l|}{ Model } \\
\hline & 1 & 2 & 3 \\
\hline & GLS & & \\
\hline $\log _{10} M_{b}$ & $-3.18 \pm 1.12^{* *}$ & $-3.03 \pm 1.12^{* *}$ & $-3.43 \pm 1.38^{* *}$ \\
\hline Drinking dependency (non-drinking) & & $0.26 \pm 0.76$ & \\
\hline prop_act & & & $-0.42 \pm 1.31$ \\
\hline Intercept & $43.24 \pm 1.69^{* *}$ & $42.83 \pm 2.08^{* *}$ & $43.78 \pm 2.42^{* *}$ \\
\hline Observations & 30 & 30 & 30 \\
\hline \multirow[t]{2}{*}{$\mathrm{AICC}$} & 120.4 & 122.3 & 122.3 \\
\hline & PGLS & & \\
\hline $\log _{10} M_{\mathrm{b}}$ & $-2.60 \pm 1.47$ & & \\
\hline Proportion sun & & & $-1.73 \pm 1.71$ \\
\hline Intercept & $41.99 \pm 3.21^{* * *}$ & $37.60 \pm 2.15^{* * *}$ & $37.98 \pm 2.18^{* * *}$ \\
\hline Observations & 30 & 30 & 30 \\
\hline $\mathrm{AICC}$ & 129.7 & 130.4 & 131.6 \\
\hline
\end{tabular}

Note: ${ }^{* *} p<0.01 ;{ }^{* * *} p<0.001$

\section{Models of rest ${ }_{50}$ and shade $_{50}$}

Our small sample size of significant rest $_{50}$ values precluded detailed interspecific analyses. In both GLS and PGLS analyses, shade 50 was best explained by the null models (see Additional file 1: Table S3). Although prop_act and forage location appeared to be influential in the top three models, none of these were significant (all $p>0.2$ ).

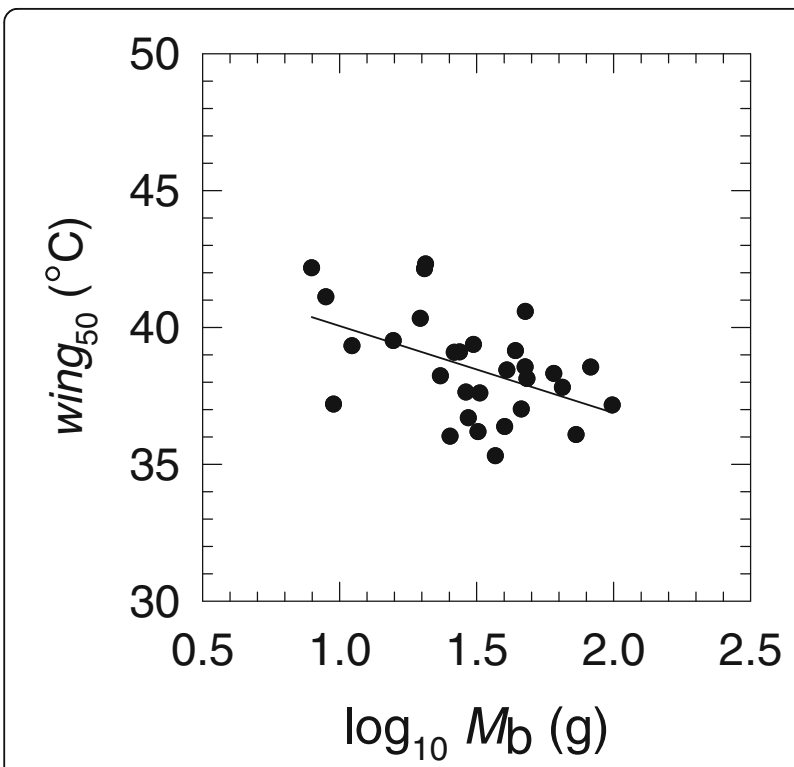

Fig. 5 Median $T_{\text {air }}$ values for wing-drooping (wing ${ }_{50}$ ) varied significantly only with $\log _{10}$ body mass $\left(\log _{10} M_{\mathrm{b}}\right)$

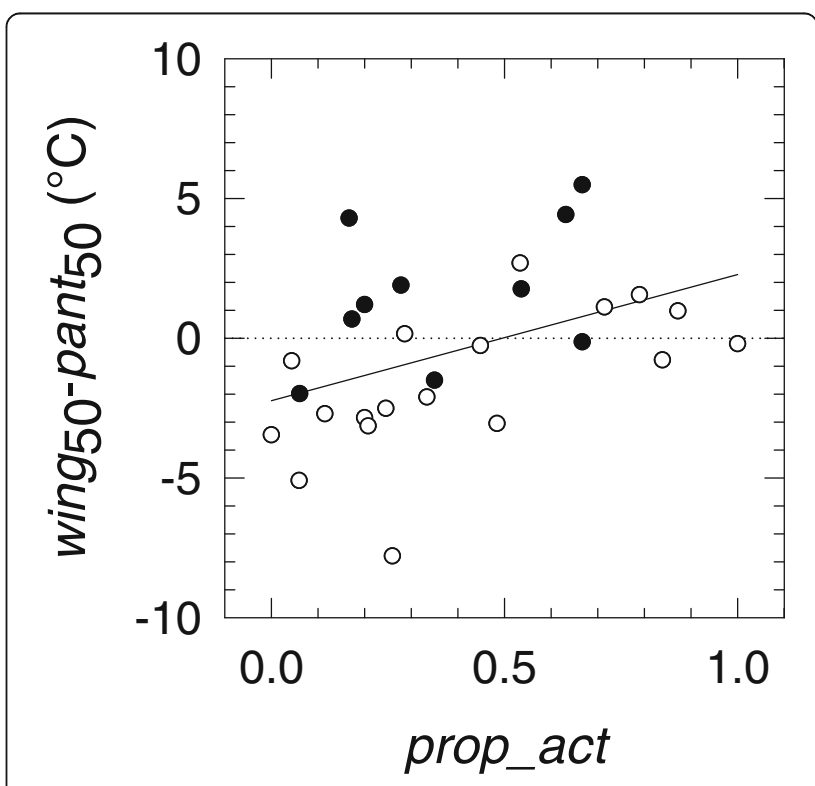

Fig. 6 Differential use of wingspreading $\left(\right.$ wing $\left._{50}\right)$ and panting/gular fluter pant $_{50}$ ), i.e. wing $_{50}$ minus pant ${ }_{50}$ values, were significantly positively correlated with activity and varied significantly with surface water drinking dependency. Species with low activity demands showed wing $_{50}$ values lower than pant 50 values, and non-drinkers showed lower wing $_{50}$ than pant ${ }_{50}$ values, compared to drinkers. Black dots and clear circles represent drinking and non-drinking species respectively 
The relationship between prop_act and body mass

Most species were active (mobile) in less than $50 \%$ of the observations (mean prop_act $=0.37$ ), but 11 species were active in more than $50 \%$ of observations (prop_act $=0.5$ to 1.0 ). A GLS showed that prop_act (logit-transformed) was significantly negatively related with $\log _{10}$ $M_{\mathrm{b}}$ (GLS: $\left.\mathrm{t}_{1,30}=-5.64, p<0.001\right)$; large species were less active (Fig. 7). Similarly, a PGLS analyses revealed that prop_act was significantly negatively correlated with $\log _{10} M_{\mathrm{b}}$ (PGLS: $\left.\mathrm{t}_{2,30}=-4.17, p<0.001\right)$.

\section{Discussion}

We found considerable interspecific variation in the temperature dependency of HDB, activity patterns and shade-seeking among the common bird species of the Kalahari Desert. Most species increased HDB at high temperatures, although reliance on respiratory HDB (i.e., pant $_{50}$ ) versus non-respiratory HDB ( wing $_{50}$ ) differed between drinking and non-drinking species. In conventional analyses, respiratory HDB thresholds varied systematically with body mass, activity levels and drinking dependency, while only $M_{\mathrm{b}}$ influenced nonrespiratory HDB thresholds. After accounting for phylogeny however, drinking dependency was the only remaining variable that explained variation in respiratory HDB. In contrast, after accounting for phylogenetic effects, non-respiratory HDB was not explained by any of the variables in our global analyses.

Importantly, non-drinking species used panting/gular flutter at higher $T_{\text {air }}$ s compared to wing-drooping. Birds

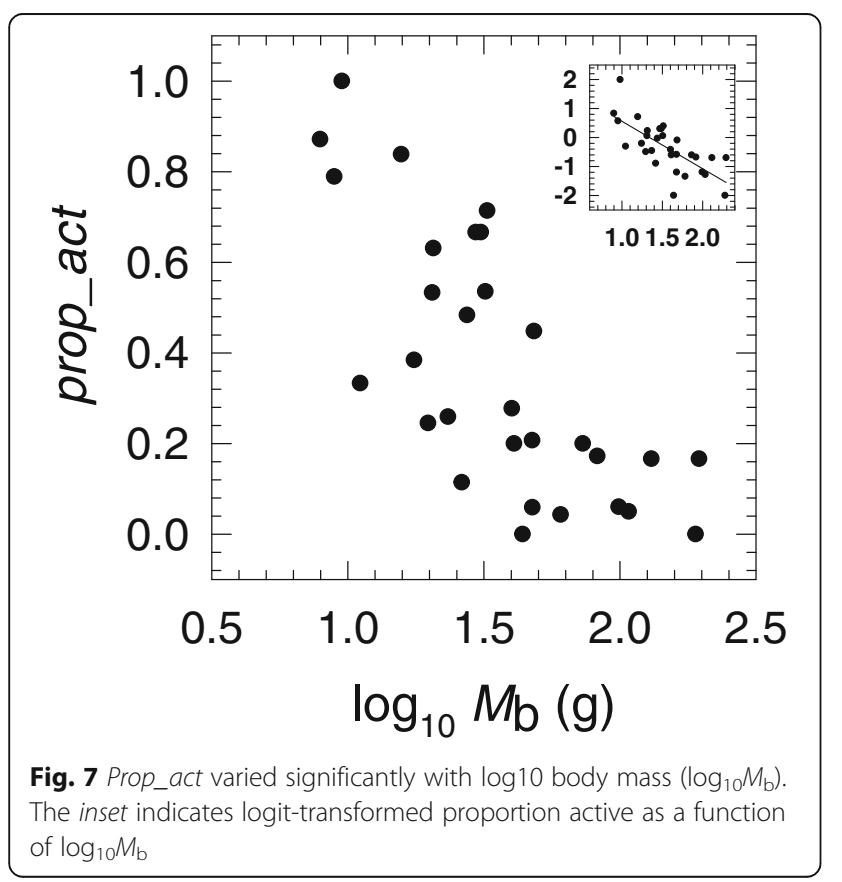

may face a trade-off between reducing their heat load through evaporative cooling (which requires water) and acquiring this water (an activity that in turn increases heat load or may incur other costs); our data suggest that drinking species afford water-costly HDB at lower a $T_{\text {air }}$ threshold, whereas non-drinking species may rely more on passive heat loss to conserve water. To the best of our knowledge, this study is the first to report on interspecific variation in HDB of free-living birds, with previous studies focusing only on single species, for example, Heermann's Gull Larus heermanni [28]; Southern Pied Babbler Turdus bicolor [13]; White-browed Sparrow-Weaver Plocepasser mahali [14]; Common Fiscal Lanius collaris [15]; Australian Magpie Cracticus tibicen [31]; and Great Knots Calidris tenuirostris [50].

\section{Conventional and phylogenetic analyses}

Our phylogenetic independent analyses provide strong support for the notion that higher pant $_{50}$ values have evolved in non-drinking species. Although $\log _{10} M_{\mathrm{b}}$ and prop_act were correlated with most categories of HDB, we found no statistical support for these relationships after taking phylogenetic relatedness into account. Both $\log _{10} M_{\mathrm{b}}$ and prop_act showed significant phylogenetic signals, suggesting these traits are phylogenetically constrained. It is therefore not clear whether the effects of $\log _{10} M_{\mathrm{b}}$ and prop_act on HDB are the result of mechanistic differences, or simply because closely related taxa are similar in mass and activity patterns. In contrast, the relationship between prop_act and $\log _{10} M_{\mathrm{b}}$ was strong, and here the effect remained important after accounting for phylogeny. We believe that the scaling effect of prop_act is linked to the scaling effects of energy-, water-, and heat balance observed in endotherms, regardless of phylogeny. We therefore argue that the correlations of HDB with $\log _{10} M_{\mathrm{b}}$ and prop_act that emerged in the conventional analyses are functionally important for understanding how species of varying $M_{\mathrm{b}}$ respond to hot conditions.

\section{Effects of body mass and activity levels on heat dissipation behaviour}

After accounting for activity levels and drinking dependency in conventional analyses, the negative relationship between pant $_{50}$ and $\log _{10} M_{\mathrm{b}}$ (albeit limited to species $<200 \mathrm{~g}$ ) observed in our study corroborates laboratory studies of avian thermoregulation at high temperatures. These studies typically show that the $T_{\text {air }}$ thresholds for initiation of panting/gular flutter and elevated EWL rates scale negatively with body mass $[18,19,35,51]$. It was hypothesized that the smaller surface area-volume ratio of larger birds should result in higher thermal inertia, and therefore, as $T_{\text {air }}$ approaches $T_{\mathrm{b}}$ the windows for passive heat 
loss become smaller for larger birds compared to small birds [35, 52]. Under these conditions, larger birds will dissipate metabolic heat more slowly via passive avenues, compared to smaller birds, and will either need to store the excess heat (i.e. facultative hyperthermia) or make use of evaporative cooling to minimise hyperthermia. Our pant $t_{50}$ data, which show that larger birds pant/gular flutter at lower $T_{\text {air }} \mathrm{s}$, support the latter point. The former option of storing excess heat in long bouts of hyperthermia has been shown to be less beneficial in large birds, as net water savings are decreased by increased pulmonary water loss at a high $T_{\mathrm{b}}$ [53]. We found a significant reduction in activity with increasing $T_{\text {air }}$ in 4/7 commonly observed species $>100 \mathrm{~g}$ (mean $159.1 \mathrm{~g}$ ). In contrast, only $9 / 39$ species $<100 \mathrm{~g}$ (mean $64.7 \mathrm{~g}$ ) showed this same pattern of reduced activity. Reduced activity translates into reduced metabolic heat load, so this finding suggests that larger birds may rely less on facultative hyperthermia and heat storage than smaller birds, perhaps for the above reasons proposed by Tieleman and Williams [53]. More detailed studies on the relationships between $M_{\mathrm{b}}$, hyperthermia and EWL, involving concurrent records of $T_{\mathrm{b}}$ patterns and HDB behaviour in birds under natural/semi-natural conditions, will be required to test these hypotheses.

It is important to note that the pattern of lower activity levels and greater heat dissipation effort that we observed in larger birds, which may imply that larger birds are at a disadvantage under climate warming, is likely linked to situations where $T_{\text {air }}<T_{\mathrm{b}}$ (as was the case in our study). At extremely high $T_{\text {air }}\left(T_{\text {air }}>T_{\mathrm{b}}\right)$, when activity is suspended in all birds regardless of $M_{\mathrm{b}}$, a different picture will emerge. Under these conditions, smaller birds, despite regulating $T_{\mathrm{b}}$ at higher levels, will still rapidly reach dehydration limits (11 to $20 \%$ of $M_{\mathrm{b}}$ ) while attempting to maintain $T_{\mathrm{b}}$ below lethal limits [51]. Larger birds, on the hand, may be less at risk during extreme heat waves as their lower mass-specific EWL, lower rates of environmental heat gain, and larger body-water pool afford them the critical window of extra survival time.

In our data set, few small species showed significant reductions in activity levels (rest $\left.t_{50}\right)$ at high $T_{\text {air }}$ : in total 11 species sustained high levels of activity (pro$p_{-}$act between 0.5 and 1.0) at hot $T_{\text {airs }}$, often while engaging in HDB. Here the relative use of respiratory versus passive heat loss, and degree of facultative hyperthermia used (discussed below) may be critical. Most active behaviour involves foraging, and high foraging effort under hot conditions may indicate strong temperature-related trade-offs [13]. Maintaining high foraging effort is likely important in arid habitats, due to the associated lower overall food availability compared to more mesic habitats [54].

\section{The role of surface water dependency in the initiation of} heat dissipation behaviour

The major pattern emerging from our data is that species that are independent of surface water showed higher thresholds for the initiation of panting and gular flutter compared with drinking species. The majority of the drinking species in our study are granivores and most non-drinkers are insectivores. The few non-drinking granivore and omnivore species (e.g. Scaly-feathered Finch Sporopipes squamifrons, and White-browed Sparrow-weaver Plocepasser mahali) also fit the above pattern, with consistently higher pant $_{50}$ values compared to granivore and omnivore drinking species (e.g. Cape Sparrow Passer melanurus and Southern Masked Weaver Ploceus velatus). For example, mean pant $t_{50}$ values were on average $5{ }^{\circ} \mathrm{C}$ higher in non-drinking omnivores $\left(40.8 \pm 3.8{ }^{\circ} \mathrm{C}, n=5\right)$ compared to drinking omnivores $\left(35.8 \pm 1.9^{\circ} \mathrm{C}, n=5\right)$.

Our findings also indicate that most non-drinking species depend on wing-drooping behaviour as the dominant form of $\mathrm{HDB}$ at $T_{\text {air }}$ between 30 and $40{ }^{\circ} \mathrm{C}$, postponing the initiation of panting/gular flutter (to higher $\left.T_{\text {air }} \mathrm{s}\right)$. This pattern is consistent among the nondrinkers and suggests behavioural and physiological responses are functionally centred on reducing evaporative water loss. Non-drinking species acquire most of their water by foraging, and therefore run the risk of expending more water on evaporative cooling while active, than they obtain through their food [17,33,54], particularly if foraging efficiency is reduced at high $T_{\text {air }}$ [13]. Wingdrooping enhances dry heat loss through convective and radiative cooling $[28,37]$, and while it is unlikely to be as efficient as evaporative cooling, it is less costly in terms of water demands.

We suggest two probable reasons for the link between drinking dependency and high levels of panting and gular flutter. First, drinking species may have more water available than non-drinking species, and consequently are able to expend more water on regulating $T_{\mathrm{b}}$. According to this scenario, we expect the expression of HDB in these species to be very sensitive to reduced water availability; i.e. HDB in drinking species should be reduced when water sources are scarce. For example, when deprived of drinking water, Emus (Dromaius novaehollandiae) reduced respiratory heat dissipation and elevated $T_{\mathrm{b}}$ compared to when water was available [55]. However, it is important to note that increased EWL is not the only cost associated with panting and gular flutter: sustained panting carries a risk of alkolosis, i.e. increased build-up of blood $\mathrm{CO}_{2}$ to dangerous levels [56, 57]. Therefore we hypothesize that birds should make use of panting or gular flutter only when the costs of hyperthermia outweigh the physiological costs associated with respiratory HDB. Species with low thresholds for panting 
or gular flutter might be more sensitive to elevations in $T_{\mathrm{b}}$, which lead to decreases in thermal performance or risk physiological damage [58]. These species will have higher evaporative cooling demands to defend stable $T_{\mathrm{b}}$, which could explain their reliance on drinking water.

We propose that $T_{\mathrm{b}}$ patterns at high $T_{\text {air }}$ in particular facultative hyperthermia, play a key role in activity and evaporative cooling trade-offs. Studies relating HDB directly to short-term changes in $T_{\mathrm{b}}$ are limited [14]. Smit et al. [14] showed that panting was initiated when $T_{\mathrm{b}}$ was above modal active-phase levels in free-ranging White-browed Sparrow-weavers (Plocepasser mahali). Because panting and gular flutter appear to represent a response to increasing $T_{\mathrm{b}}$, potentially approaching lethal limits $\left[44-46{ }^{\circ} \mathrm{C},[22]\right.$ ), we hypothesise that variation in thresholds of panting/gular fluttering is related to variation in tolerance of a raised $T_{\mathrm{b}}$. We predict that non-drinking species likely make use of facultative hyperthermia [14] under free-living conditions to a greater extent than drinking species.

\section{Considerations when undertaking this approach}

In our study we identified a number of limitations in using heat dissipation and behavioural patterns as a proxy for thermoregulatory demands in bird communities. First, the utility of the method presented here is likely to be limited to relatively open habitat, such as arid regions, where birds can be observed when they are inactive. Second, collecting data at a community level requires that most species are fairly abundant in the community, i.e. species evenness should be high. In many cases workers will need to increase search effort for less abundant species to obtain a community level data set. Third, in cases where a median $T_{\text {air }}$ value for HDB cannot be established, an alternative metric for behavioural responses would therefore be to simply use proportional values. In all cases, prop_pant or prop_wing values were highly correlated with their respective median $T_{\text {air }}$ values of HDB (see Additional file 1: Figure S1). Median values seem a good predictor of the percentage of time a behaviour is expressed during hot temperatures and represent functional differences in activity time-budgets.

Finally, some avian taxa, such as the order Columbiformes, are expected to make substantial use of cutaneous evaporative cooling [59-61]. Panting or gular flutter behaviour will greatly underestimate evaporative heat dissipation efforts in these taxa. In our study we found that the pant $t_{50}$ values for two species of dove, Namaqua Dove and Cape Turtle Dove, were higher than for similar sized passerines in our data-set, and represented influential outliers. The low incidence of panting and gular flutter observed in doves could be explained by the highly efficient evaporative cooling rates recently shown for this taxon [62, 63]. In contrast, the order
Passeriformes have a limited capacity for cutaneous evaporative cooling at high temperatures [64-66]. We argue that, with the exception of the Columbiformes, cutaneous evaporative cooling is unlikely to be an important avenue of heat loss at high temperatures in most of the species observed in our study, especially the nondrinking species, since cutaneous evaporative cooling will be expensive when water sources are scarce.

\section{Heat dissipation behaviour as a proxy for vulnerability} Many regions in South Africa have shown sustained climate warming over the past few decades, i.e. 1990s to 2010s [67, 68]. Moreover, globally, the years of 2015/ 2016 have been the warmest on record. During the austral summer of 2015/2016 most of the semi-arid and arid-zone regions of South Africa experienced record monthly maximum temperatures (in some cases 3 to $5{ }^{\circ} \mathrm{C}$ above average) and all-time record maxima were observed country wide (https://www.wunderground.com). It seems evident that over the next few decades many avian populations will more frequently experience $T_{\text {air }} \mathrm{s}$ that will elevate water demands and behavioural trade-offs. Our data show that species vary in their behavioural and thermoregulatory responses to high temperatures. Some of the species included in our study have already been shown to experience challenging trade-offs at $T_{\text {air }}$ between 30 and $40{ }^{\circ} \mathrm{C}$. For example, Common Fiscals (Lanius collaris) show changes in shade-seeking behaviour leading to reduced prey capture and provisioning rates, compromising breeding success $[15,16]$ and White-browed Sparrow-weavers show elevated $T_{\mathrm{b}}$ [14] and mismatches between daily water intake and water loss [17]. Common Fiscals and White-browed Sparrow-weavers have relatively high pant $t_{50}$ values of 40 and $46{ }^{\circ} \mathrm{C}$, respectively, whereas $58 \%$ of species in our data set had pant 50 values below $40{ }^{\circ} \mathrm{C}$. We therefore predict that most of the latter species are already vulnerable to increasing $T_{\text {air }}$.

\section{Conclusion}

This study presents a novel method for large-scale and low-cost assessment of variation in behavioural patterns of heat stress in bird communities. Our study shows that systematic inter-specific variation in panting and gular flutter is related to the drinking ecology of species, and to some extent, their body mass and activity patterns. We propose that this approach could greatly supplement integrative studies on the trade-offs between energy and water demands, foraging effort and thermoregulation under hot conditions. We further propose that this method could be developed as a proxy for investigating community-level response to high temperatures, and that it would be particularly relevant to predict vulnerability to climate warming scenarios. However, to fully understand the thermal physiological trade-offs 
associated with heat dissipation thresholds we still need to determine if variation in pant $_{50}$ is associated with specieslevel physiological differences, other than those driven by intrinsic factors such as body mass and activity demands. A small number of studies have already demonstrated that HDBs represent behavioural trade-offs with potential fitness consequences [13]. However, to further understand links between HDB and thermal physiological trade-offs that may underpin vulnerability, further investigation should address the following questions: 1 ) what are the relationships between heat dissipation patterns and $T_{\mathrm{b}}$ regulation? We predict that lower pant ${ }_{50}$ and wing s0 $_{5}$ values could be related to lower tolerance of $T_{\mathrm{b}}$ elevations; 2 ) is heat dissipation effort indicative of dehydration risk? We predict species with low pant $t_{50}$ values to show greater daily water demands and a greater risk of dehydration on hot days; 3) How flexible are temperature-related HDB, activity and $T_{\mathrm{b}}$ patterns as a result of food and water supply? We predict that there will be variation in species' capacity to adjust their thermoregulatory patterns and this may be linked to adaptation to arid environments. In conclusion, our study shows that interspecific variation in HDBs, together with information on body size, physiology and ecology has the potential to provide community-level assessments of the thermoregulatory trade-offs that species confront at high $T_{\text {airs }}$. We hope that, together with further research on the relationships between HDBs, $T_{\mathrm{b}}$ regulation and dehydration risk, these findings will form a foundation for using low-cost field-based observational studies to assess vulnerability to climate change.

\section{Additional file}

Additional file 1: Summary of heat dissipation observations and statistics. (DOCX $82 \mathrm{~kb}$ )

Additional file 2: Behavioural observation data of birds collected during the austral summers (November-March) of 2009/2010 and 2010/2011. (XLSX $1.09 \mathrm{mb}$ )

Additional file 3: Raw data as presented in Table S1 and Table S2. (XLSX $63 \mathrm{~kb}$ )

\footnotetext{
Abbreviations

BEMs: Bioclimatic envelope models; EWL: Evaporative water loss; GLS: Generalized linear models; HDB: Heat dissipation behaviour; $M_{\mathrm{b}}$ : Body mass; pant ${ }_{50}$ : Air temperature where panting behaviour occur in $50 \%$ of cases; PGLS: Phylogenetic generalized linear models; prop_act: Proportion of observations where birds were mobile at air temperatures between 35 and $40{ }^{\circ} \mathrm{C}$; prop_pant: Proportion of observations where birds were panting at air temperatures between 35 and $40{ }^{\circ} \mathrm{C}$; prop_sun: Proportion of observations where birds were exposed to full sun at air temperatures between 35 and $40{ }^{\circ} \mathrm{C}$; prop_wing: Proportion of observations where birds were wingdrooping at air temperatures between 35 and $40{ }^{\circ} \mathrm{C}$; rest $t_{50}$ : Air temperature where resting behaviour occur in $50 \%$ of cases; shade ${ }_{50}$ : Air temperature where shade-seeking behaviour occur in $50 \%$ of cases; $T_{\text {air }}$ : Air temperature; $T_{\mathrm{b}}$ : Body temperature; wing $_{50}$ : Air temperature where wing-drooping behaviour occur in $50 \%$ of cases
}

\section{Acknowledgements}

We thank E Oppenheimer and Son, and the Tswalu Foundation for sponsoring a field vehicle and accommodation at TKR. We thank Robert Sutcliffe, David Nkosi, Dawn Cory Toussaint, Carol Hoole, Hardie van Tonder, Elsabie Templeton and Jorge Berdón for their assistance in the field. We thank Tom Flower for collecting additional data on some species. Maxine Whitfield is thanked for her valuable comments on the discussion of the manuscript.

\section{Funding}

This research was supported by funding from National Research Foundation and the DST-NRF Centre of Excellence at the Percy FitzPatrick Institute to $\mathrm{AEM}$ and $\mathrm{PARH}$.

\section{Availability of data and material}

All raw data are available in Aditional file 2.

\section{Authors' contributions}

BS, ROM, SJC, AEM and PARH developed the conceptual framework. BS, ROM and GZ collected data. BS analysed conducted data analyses. BS and AEM wrote the manuscript. ROM and SJC edited the manuscript. All authors read and approved the final manuscript.

\section{Competing interests}

The authors declare that they have no competing interests.

\section{Consent for publication}

We have obtained consent to publish the data collected by Tom Flower at KRR. We declare there are no further contents of this manuscript that require consent to be published.

Ethics approval and consent to participate

Not applicable.

\section{Author details}

${ }^{1}$ Department of Zoology, Nelson Mandela Metropolitan University, PO Box 77000, Port Elizabeth 6031, South Africa. ${ }^{2}$ Percy FitzPatrick Institute of African Ornithology, DST-NRF Centre of Excellence, University of Cape Town, Rondebosch 7701, South Africa. ${ }^{3}$ DST-NRF Centre of Excellence at the Percy FitzPatrick Institute, Department of Zoology and Entomology, University of Pretoria, Private Bag X20, Hatfield 0028, South Africa.

Received: 25 June 2016 Accepted: 28 September 2016

Published online: 20 October 2016

References

1. Thomas CD, Cameron A, Green RE, Bakkenes M, Beaumont L, Collingham YC, Erasmus BFN, Ferreira de Siqueira M, Grainger A, Hannah L, et al. Extinction risk from climate change. Nature. 2004;427:145-8.

2. Araújo MB, Thuiller W, Pearson RG. Climate warming and the decline of amphibians and reptiles in Europe. J Biogeogr. 2006;33:1712-28.

3. Huntley B, Collingham YC, Green RE, Hilton GM. Potential impacts of climate change upon geographical distributions of birds. Ibis. 2006;148:8-28.

4. Lawler JJ, Shafer SL, White D, Kareiva P, Maurer EP. Projected climateinduced faunal change in the Western Hemisphere. Ecology. 2009;90(3): 588-97.

5. Thomas CD, Franco AMA, Hill JK. Range retractions and extinction in the face of climate warming. Trends in Ecology and Evolution. 2006:21(8):415-6.

6. Peterson AT. Predicting species' geographical distributions based on ecological niche modeling. Condor. 2001;103:599-605.

7. Briscoe NJ, Handasyde KA, Griffiths SR, Porter WP, Krockenberger AK, Kearney MR. Tree-hugging koalas demonstrate a novel thermoregulatory mechanism for arboreal mammals. Biol Lett. 2014;10:20140235.

8. Briscoe NJ, Kearney MR, Taylor CA, Wintle BA. Unpacking the mechanisms captured by a correlative species distribution model to improve predictions of climate refugia. Glob Chang Biol. 2016;22(7):2425-39.

9. Kearney M, Porter WP, Williams C, Ritchie S, Hoffmann AA. Integrating biophysical models and evolutionary theory to predict climatic impacts on species' ranges: the dengue mosquito Aedes aegypti in Australia. Funct Ecol. 2009;23(3):528-38. 
10. Kearney MR, Wintle BA, Porter WP. Correlative and mechanistic models of species distribution provide congruent forecasts under climate change. Conserv Lett. 2010;3(3):203-13.

11. Humphries MM, Thomas DW, Speakman JR. Climate-mediated energetic constraints on the distribution of hibernating mammals. Nature. 2002;418: 313-6.

12. Krockenberger AK, Edwards W, Kanowski J. The limit to the distribution of a rainforest marsupial folivore is consistent with the thermal intolerance hypothesis. Oecologia. 2012;168:889-99.

13. du Plessis KL, Martin RO, Hockey PAR, Cunningham SJ, Ridley AR. The costs of keeping cool in a warming world: implications of high temperatures for foraging, thermoregulation and body condition of an arid-zone bird. Glob Chang Biol. 2012;18:3063-70.

14. Smit B, Harding CT, Hockey PAR, McKechnie AE. Adaptive thermoregulation during summer in two populations of an arid-zone passerine. Ecology. 2013; 94(5):1142-54.

15. Cunningham SJ, Martin RO, Hockey PAR. Can behaviour buffer the implacts of climate change on an arid-zone bird? Ostrich. 2015;86(1-2):119-26.

16. Cunningham SJ, Martin RO, Hojem CL, Hockey PAR. Temperatures in excess of critical thresholds threaten nestling growth and survival in a rapidlywarming arid savanna: a study of common fiscals. PLoS One. 2013;8(9):e74613.

17. Smit B, McKechnie AE. Water and energy fluxes during summer in an aridzone passerine bird. Ibis. 2015;57(4):774-86.

18. Milne R, Cunningham SJ, Lee ATK, Smit B. The role of thermal physiology in recent declines of birds in a biodiversity hotspot. Conservation Physiology. 2015;3(1):cov048

19. Whitfield MC, Smit B, McKechnie AE, Wolf BO. Avian thermoregulation in the heat: scaling of heat tolerance and evaporative cooling capacity in three southern African arid-zone passerines. J Exp Biol. 2015;218:1705-14.

20. Bakken GS. Measurement and application of operative temperatures in ecology. Am Zool. 1992;32(2):194-216.

21. Wolf $\mathrm{BO}$, Walsberg GE. Thermal effects of radiation and wind on a small bird and implications for microsite selection. Ecology. 1996;77(7):2228-36.

22. Dawson WR. Temperature regulation and water requirements of the brown and Abert towhees, Pipilo fuscus and Pipilo aberti. In: Bartholomew GA, Crescitelli F, Bullock TH, Furgason WH, Schechtman AM, editors. University of California Publications in Zoology, vol. 59. Berkeley: University of California Press; 1954. p. 81-123.

23. Dawson WR, Whittow GC. Regulation of body temperature. In: Whittow GC, editor. Sturkie's avian physiology. New York: Academic Press; 2000. p. 343-90.

24. Bartholomew GA, Dawson WR. Body temperatures in California and Gambel's quail. Auk. 1958:75:150-6.

25. Bartholomew GA. Body temperature and energy metabolism. In: Gordon MS, editor. Animal physiology: principles and adaptation. New York: Macmillan; 1972. p. 298-368.

26. Finlayson $\mathrm{HH}$. Heat in the interior of South Australia - holocaust of bird-life. South Australian Ornithologist. 1932;11:158-60.

27. Saunders DA, Mawson P, Dawson R. The impact of two extreme weather events and other causes of death on Carnaby's Black Cockatoo: a promise of things to come for a threatened species? Pac Conserv Biol. 2011;17:141-8.

28. Bartholomew GA, Dawson WR. Thermoregulatory behavior during incubation in Heermann's Gulls. Physiol Zool. 1979;52(4):422-37.

29. Bartholomew GA, Hudson JW, Howell TR. Body temperature, oxygen consumption, evaporative water loss, and heart rate in the poor-will. Condor. 1962:64(2):117-25.

30. Lasiewski RC, Bartholomew GA. Evaporative cooling in the poor-will and the tawny frogmouth. Condor. 1966;68:253-62.

31. Edwards EK, Mitchell NJ, Ridley AR. The impact of high temperatures on foraging behaviour and body condition in the Western Australian Magpie (Cracticus tibicen dorsalis). Ostrich. 2015;86(1-2):137-44.

32. Catry I, Catry T, Patto P, Franco AMA, Moreira F. Differential heat tolerance in nestlings suggests sympatric species may face different climate change risks. Clim Res. 2015;66(1):13-24.

33. Tieleman BI, Williams JB, Visser $\mathrm{GH}$. Variation in allocation of time, wate and energy in hoopoe larks from the Arabian Desert. Funct Ecol. 2003; 17:869-76.

34. Martin RO, Cunningham SJ, Hockey PAR. Elevated temperatures drive finescale pattern of habittat use in a savanna bird community. Ostrich. 2015; 86(1-2):127-35.

35. Weathers WW. Physiological thermoregulation in heat-stressed birds: consequences of body size. Physiol Zool. 1981;54(3):345-61.
36. Dawson WR, Bartholomew GA. Temperature regulation and water economy of desert birds. In: Brown GW, editor. Desert biology. New York: Academic Press; 1968.

37. Dawson WR, Hudson JW. Birds. In: Whittow GC, editor. Comparitive physiology of thermoregulation. New York: Academic Press; 1970. p. 223-310.

38. R Core Team. R: a language and environment for statistical computing. Vienna: R Foundation for Statistical Computing; 2012.

39. Gerson AR, Smith EK, Smit B, McKechnie AE, Wolf BO. The impact of humidity on evaporative cooling in small desert birds exposed to high air temperatures. Physiol Biochem Zool. 2014;87(6):782-95.

40. Paradis E, Bolker B, Claude J, Cuong H, Desper R, Du-rand B, Dutheil J, Gascuel O, Heibl C, Lawson D, et al. ape: analyses of phylogenetics and evolution. 2013.

41. Orme D, Freckleton R, Thomas G, Petzoldt T, Fritz S, Isaac N, Pearse W. caper: comparative analyses of phylogenetics and evolution in R. 2013.

42. Hockey PAR, Dean WRJ, Ryan PG. Roberts birds of southern Africa. 7th ed. Cape Town: John Voelcker Bird Book Fund; 2005.

43. Jetz W, Thomas GE, Joy JB, Hartmann K, Mooers AO. The global diversity of birds in space and time. Nature. 2012;491:444-8.

44. Hackett SJ, Kimball RT, Reddy S, Bowie RCK, Braun EL, Braun MJ, Chojnowski JL, Cox WA, Han K-L, Harshman J, et al. A phylogenomic study of birds reveals their evolutionary history. Science. 2008:320:1763-8.

45. Mesquite: a modular system for evolutionary analysis. Version 2.75. http:// mesquiteproject.org

46. Burnham KP, Anderson DR. Model selection and multi-model inference: a practical information-theoretic approach. 2nd ed. New York: Springer; 2002.

47. Barton K. MuMIn: Multi-model inference. R package version 0.13.17. In: https://cran.r-project.org/web/packages/MuMln/index.html. 2010

48. Warton DI, Hui FKC. The arcsine is asinine: the analysis of proportions in ecology. Ecology. 2011;92(1):3-10.

49. Blomberg SP, Garland T, Ives AR. Testing for phylogenetic signal in comparative data: behavioral traits are more labile. Evolution. 2003:57(4):717-45.

50. Battley PF, Rogers DI, Piersma T, Koolhaas A. Behavioural evidence for heatload problems in Great Knots in tropical Australia fuelling for long-distance flight. Emu. 2003;103(2):97-103.

51. McKechnie AE, Wolf BO. Climate change increases the likelihood of catastrophic avian mortality events during extreme heat waves. Biol Lett. 2010;6:253-6.

52. Calder WA, King JR. Thermal and caloric relations of birds. In: Farner DS, King JR, editors. Avian biology, vol. 4. New York: Academic Press; 1974. p. 259-413.

53. Tieleman BI, Williams JB. The role of hyperthermia in the water economy of desert birds. Physiol Biochem Zool. 1999;72(1):87-100.

54. Tieleman BI, Williams JB. Effects of food supplementation on behavioural decisions of hoopoe-larks in the Arabian Desert: balancing water, energy and thermoregulation. Anim Behav. 2002;63:519-29.

55. Maloney SK, Dawson WR. Changes in pattern of heat loss at high ambient temperature caused by water deprivation in a large flightless bird, the emu. Physiol Zool. 1998;71(6):712-9.

56. Calder W, Schmidt-Nielsen K. Panting and blood carbon dioxide in birds American Journal of Physiology - Legacy Content. 1968;215(2):477-82.

57. Marder J, Arad Z. Panting and acid-base regulation in heat stressed birds. Comp Biochem Physiol A Physiol. 1989;94(3):395-400.

58. Boyles JG, Seebacher F, Smit B, McKechnie AE. Adaptive thermoregulation in endotherms may alter responses to climate change. Integr Comp Biol. 2011:51(5):676-90

59. Hoffman TCM, Walsberg GE. Inhibiting ventilatory evaporation produces an adaptive increase in cutaneous evaporation in mourning doves Zenaida macroura. J Exp Biol. 1999;202(21):3021-8.

60. Marder J, Arieli U. Heat balance of acclimated pigeons Columba livia exposed to temperatures of up to $60{ }^{\circ} \mathrm{C} T_{a}$. Comp Biochem Physiol. 1988; 91A:165-70.

61. McKechnie AE, Wolf BO. Partitioning of evaporative water loss in whitewinged doves: plasticity in response to short-term thermal acclimation. J Exp Biol. 2004:207:203-10.

62. McKechnie AE, Whitfield MC, Smit B, Gerson AR, Smith EK, Talbot WA, McWhorter TJ, Wolf BO. Avian thermoregulation in the heat: efficient evaporative cooling allows for extreme heat tolerance in four southern Hemisphere columbids. J Exp Biol. 2016;219:2145-55.

63. Smith EK, O'Neill J, Gerson AR, Wolf BO. Avian thermoregulation in the heat: resting metabolism, evaporative cooling and heat tolerance in Sonoran Desert doves and quail. J Exp Biol. 2015;218(22):3636-46. 
64. Wolf BO, Walsberg GE. Respiratory and cutaneous evaporative water loss at high environmental temperatures in a small bird. J Exp Biol. 1996;199:451-7.

65. Tieleman BI, Williams JB. Cutaneous and respiratory water loss in larks from arid and mesic environments. Physiol Biochem Zool. 2002;75(6):590-9.

66. Ro J, Williams JB. Respiratory and cutaneous water loss of temperate-zone passerine birds. Comparative Biochemistry and Physiology A. 2010;156:237-46.

67. van Wilgen NJ, Goodall V, Holness S, Chown SL, McGeoch MA. Rising temperatures and changing rainfall patterns in South Africa's national parks. Int J Climatol. 2016;36(2):706-21.

68. Kruger AC, Sekele SS. Trends in extreme temperature indices in South Africa: 1962-2009. Int J Climatol. 2013;33:661-76.

Submit your next manuscript to BioMed Central and we will help you at every step:

- We accept pre-submission inquiries

- Our selector tool helps you to find the most relevant journal

- We provide round the clock customer support

- Convenient online submission

- Thorough peer review

- Inclusion in PubMed and all major indexing services

- Maximum visibility for your research

Submit your manuscript at www.biomedcentral.com/submit
C) Biomed Central 